2. Gammon, M. D. et al. Environmental toxins and breast cancer on Long Island. 1. Polycyclicaromatic hydrocarbon DNA adducts. Cancer Epidemiol. Biomarkers Prev. 11 , 677-685 (2002).

3. Muscat, J. E. et al. Adipose concentrations of organochlorine compounds and breast cancer recurrence in Long Island, New York. Cancer Epidemiol. Biomarkers Prev. 12, 14741478 (2003).

4. O'Leary, E. S., et al. Pesticide exposure and risk of breast cancer: a nested case-control study of residentially stable women living on Long Island. Environ. Res. 94, 134-144 (2004).

5. McKelvey, R. A., Wright, J. P. \& Honegger, J. L. A comparison of crop and non-crop plants as sensitive indicator species for regulatory testing. Pest. Manag. Sci. 58, $1161-$ 1174 (2002).

6. Kennedy, D. O. et al. DNA repair capacity of lymphoblastoid cell lines from sisters discordant for breast cancer. J. Natl Cancer Inst. 97, 127-132 (2005).

\title{
The author responds
}

\section{Deborah M. Winn}

Clinical and Genetic Epidemiology Research Branch, Epidemiology and Genetics Research Program, Division of Cancer Control and Population Sciences, Executive Plaza North, Room 5134, MSC 7393, 6130 Executive Boulevard, Bethesda, Maryland, 20892-7393, USA.

Correspondence to D.M.W.

e-mail:winnde@mail.nih.gov

I thank Donovan et al. for their letter in response to my article "The Long Island Breast Cancer Study Project"1. I concluded that "there is no evidence that environmental exposures were responsible" for breast cancer incidence patterns on Long Island ${ }^{1}$. My conclusion was based on the body of epidemiological evidence taken together from the studies comprising the Long Island Breast Cancer Study Project (LIBCSP). Overall there were no significant risks from the main chemical and physical agents studied (organochlorines, polycyclic aromatic hydrocarbons (PAHs), and electromagnetic fields). Of the three studies that Donovan and colleagues cited, the first, which found a modest increased breast cancer risk in the women with the highest exposure to polycyclic aromatic hydrocarbons ${ }^{2}$, is intriguing, but no dose-response relationship with levels of exposure was observed. There also was no dose-response for breast cancer risks for women by distance of residence within a half mile and a half-one mile radius, relative to a greater than one mile radius, from a hazardous waste site containing pesticides ${ }^{3}$. The third study cited examined recurrence ${ }^{4}$, not a first breast cancer diagnosis, which is used in computing incidence rates.

The authors correctly stress the importance of good control selection in case-control studies of environmental agents and cancer risk. For example, one would not want to select a control for a case with cancer from the same neighborhood as the case in a study of a physical or chemical environmental agent. This would virtually guarantee that cases and controls would be similar on environmental exposure patterns even if there were a causal relationship between the environmental exposure and the cancer. The investigators of the case-control studies included in the LIBCSP used two types of control selection in their studies: population-based controls for population-based cases (all cases in a broad geographic area) drawn from the general population within that area, and hospital-based controls for hospital-based cases ${ }^{1}$. Their selection criteria for controls was not based on the geographic residence of the individual cases, and so the possibility of diluting the potential magnitude effect of environmental factors because of the similarity of cases and controls with respect to residence was not an issue.

As Donovan et al. pointed out, there could be people who are more susceptible to the effects of environmental agents than others. For example, Terry et al. ${ }^{5}$ reported additional findings from the Breast Cancer and the Environment on Long Island Study, the largest of the case-control studies. Women with a certain polymorphism in the DNA-repair gene XPD might be at increased risk of breast cancer from PAHDNA adducts, which reflect exposure to and repair of DNA damage from PAHs. One minor point is that 
people at genetically higher risk would not necessarily develop the cancer at an earlier age as the authors suggest, because cancer is a multi-step process and the genetic factors could operate through biological mechanisms that are unrelated to age at cancer diagnosis.

I thank the authors for expanding on the many challenges of studying the role of environmental factors and cancer and for pointing out the potential differences among people in their susceptibility to environmental agents.

1. Winn, D. M. The Long Island Breast Cancer Study Project. Nature Reviews Cancer 5, 986994, (2005).

2. Gammon, M. D. et al. Environmental toxins and breast cancer on Long Island. I. Polycyclic aromatic hydrocarbon DNA adducts. Cancer Epidemiol. Biomarkers Prev. 1 1, 677-685 (2002).

3. O'Leary, E. S., Vena, J. E., Freudenheim, J. L., Brasure, J. Pesticide exposure and risk of breast cancer: a nested case-control study of residentially stable women living on Long Island. Environ Res. 94, 134-144 (2004).

4. Muscat, J. E. et al. Adipose concentrations of organochlorine compounds and breast cancer recurrence in Long Island, New York. Cancer Epidemiol. Biomarkers Prev. 12, 1474-1478 (2003).

5. Terry, M. B. et al. Polymorphism in the DNA repair gene XPD, polycyclic aromatic hydrocarbon-DNA adducts, cigarette smoking, and breast cancer risk. Cancer Epidemiol. Biomarkers Prev. 13, 2053-2058 (2004). 